\title{
Xanthogranulomatous Pyelonephritis Associated with Crohn's Disease and Primary Hyperparathyroidism
}

\author{
Mekdess Abebe, Wing Mu, Heesuck Suh, Edward P. Nord, \\ Nand K. Wadhwa* \\ Division of Nephrology, Department of Medicine, School of Medicine, State University of New York at Stony Brook, \\ Stony Brook, USA \\ Email: *nand.wadhwa@stonybrookmedicine.edu
}

Received May 15, 2013; revised June 20, 2013; accepted July 3, 2013

Copyright (C) 2013 Mekdess Abebe et al. This is an open access article distributed under the Creative Commons Attribution License, which permits unrestricted use, distribution, and reproduction in any medium, provided the original work is properly cited.

\begin{abstract}
We report on a case of unilateral and diffuse xanthogranulomatous pyelonephritis (XGP) associated with Crohn's disease and primary hyperparathyroidism (HPT). The patient had undiagnosed primary HPT for at least a year prior to presentation. The co-existence of Crohn's disease and primary HPT caused calcium oxalate stone likely by the known mechanism of hypercalcemia and hyperoxaluria respectively. The patient developed XGP, a rare disease, as a result of infected calcium oxalate stone which was treated with antibiotics and unilateral nephrectomy. To the best of our knowledge, this is the first case of XGP associated with Crohn's disease and primary HPT.
\end{abstract}

Keywords: Xanthogranulomatous Pyelonephritis; Hyperparathyroidism; Crohn’s; Hypercalcemia

\section{Introduction}

XGP is a rare, serious, chronic inflammatory disorder of the kidney and constitutes less than $1 \%$ of chronic pyelonephritis. It is characterized by destruction of renal parenchyma and its replacement with granulomatous, abscess and collection of lipid laden macrophage (xanthoma cells) [1]. The disease most frequently presents in middle-aged groups with a predilection for female gender [2]. XGP shares many characteristics with renal neoplasm in terms of its radiologic appearance and its ability to invade adjacent structures. We report a case of unilateral and diffuse XGP due to undiagnosed primary HPT and Crohn's disease leading to unilateral nephrectomy.

\section{Case Report}

A 46-year-old white woman presented to emergency department with a two week history of right flank pain associated with generalized weakness, dizziness, decreased appetite and weight loss of 50 pounds in the last few months. She also had shortness of breath at minimal exertion. She denied any urinary complaint, fever, nausea or vomiting. Her significant comorbidities included Crohn's disease diagnosed in 2009, small bowel obstruction due to Crohn's disease related stricture resulting in

\footnotetext{
*Corresponding author.
}

laparoscopic small bowel resection in 2010, chronic pancreatitis and bilateral kidney stones. Patient was not on any medication prior to admission. She was an active smoker but denied alcohol or illegal drug use.

At presentation, the patient was not in any distress. Blood pressure was 97/53 mmHg, pulse 92 beats/minute and temperature was $38.3^{\circ} \mathrm{C}$. She had dry oral mucosa. Abdominal examination showed mildly distended abdomen with right costovertebral angle tenderness. No organomegally was appreciated. The remainder of the physical examination was within normal limits. Laboratory evaluation showed white blood cell count of $11.8 \times 10^{3}$ /mcL, hemoglobin $7.5 \mathrm{~g} / \mathrm{dL}$, hematocrit $22.4 \%$ and platelet count of $397 \times 10^{3} / \mathrm{mcL}$. Serum chemistry showed a sodium of $134 \mathrm{mEq} / \mathrm{L}(134 \mathrm{mmol} / \mathrm{L})$, potassium 3.8 $\mathrm{mEq} / \mathrm{L}(3.8 \mathrm{mmol} / \mathrm{L})$, chloride $111 \mathrm{mEq} / \mathrm{L}(111 \mathrm{mmol} / \mathrm{L})$, bicarbonate $13 \mathrm{mEq} / \mathrm{L}(13 \mathrm{mmol} / \mathrm{L})$, blood urea nitrogen $60 \mathrm{mg} / \mathrm{dL}(21.4 \mathrm{mmol} / \mathrm{L})$, serum creatinine $3.6 \mathrm{mg} / \mathrm{dL}$ (275 $\mu \mathrm{mol} / \mathrm{L}$ ) (her serum creatinine was $0.8 \mathrm{mg} / \mathrm{dL}$ (61 $\mu \mathrm{mol} / \mathrm{L}) 6$ months prior to this admission), ionized calcium $5.4 \mathrm{mg} / \mathrm{dL}(1.35 \mathrm{mmol} / \mathrm{L})$, total calcium $9.8 \mathrm{mg} / \mathrm{dL}$ (2.45 mmol/L), corrected calcium for albumin $10.8 \mathrm{mg} /$ $\mathrm{dL}(2.7 \mathrm{mmol} / \mathrm{L})$, phosphorous $5.2 \mathrm{mg} / \mathrm{dL}(1.68 \mathrm{mmol} / \mathrm{L})$, albumin $2.8 \mathrm{mg} / \mathrm{dL}$ and total protein $6.1 \mathrm{mg} / \mathrm{dL}$. Liver function tests were within normal limits. Anti nuclear antibody was positive at 1:320. Serum protein electrophoresis (SPEP), urine protein electrophoresis (UPEP), C3, 
C4, antineutrophil cytoplasmic antibodies, Anti ds DNA antibodies were negative. Urinalysis showed large leukocyte esterase, WBC > 182 and protein $100 \mathrm{mg} / \mathrm{dL}$. Urine culture was negative.

Intravenous ceftriaxone and ciprofloxacin therapy was started for presumed pyelonephritis. Patient also received IV hydration with normal saline and 4 units of packed RBC. Renal ultrasound and non-contrast computed tomography (CT) of the abdomen showed multiple heterogeneous and solid appearing lobular soft tissue masses at the periphery of the mid and lower pole of the right kidney that extends into the peri-renal space which was suspicious for malignancy (Figure 1). Bilateral kidney stones were recognized on CT. MRI of the abdomen demonstrated enlarged right kidney with some increased parenchymal signal intensity with poorly defined margin with peri-nephric infection. However, Indium scan revealed no evidence of pyelonephritis or renal abscess. Medical therapy with IV hydration and antibiotics, initially ceftriaxone and ciprofloxacin, later aztreonam for a total of 4 weeks were administered. In view of her hypercalcemia, she was investigated further and was found to have elevated serum PTH of $390 \mathrm{pg} / \mathrm{mL}$. A sestamebi scan and an ultrasound of the neck revealed a right parathyroid adenoma.

Two weeks after admission, because of persistence of the right renal mass, CT guided percutaneous biopsy was performed and revealed 43 cc of turbid fluid which was negative for malignant cells and culture. Further testing of the right kidney function using furosemide renal scan demonstrated residual renal function of $<10 \%$. Subsequently, due to suspicion of malignancy in the face of non functioning and possibly infected right kidney, patient underwent right nephrectomy 5 weeks after admission. Gross examination showed a peri-nephric fat adherent to the capsule of the kidney with fat necrosis and diffuse yellow-red hemorrhagic tissue (Figure 2(A)). There was also a $2 \mathrm{~cm}$ yellow crushable stone at the distal ureter occupying the entire lumen. Histopathology revealed acute and moderate chronic inflammation with focal marked increased interstitial eosinophils and lipid laden macrophage (xanthoma cells) (Figure 2(B)), consistent with XGP pyelonephritis. There was also nephrocalcinosis, both polarizable and non-polarizable. Chemical analysis of the stone revealed calcium oxalate stone. Simultaneously right para- thyroidectomy was also performed for parathyroid adenoma. After six weeks of hospital stay, her serum creatinine level was stable at 2.1 $\mathrm{mg} / \mathrm{dl}(160 \mu \mathrm{mol} / \mathrm{L})$ and was discharged in a stable condition.

\section{Discussion}

We report on a case of XGP associated with Crohn's disease and primary HPT which was unrecognized for at least a year prior to her present presentation. The co- existence of primary HPT and Crohn's disease caused calcium oxalate stone by the known mechanisms of hypercalcemia and hyperoxaluria respectively. To the best of our knowledge, this is the first case of XGP secondary to Crohn's disease and primary HPT which in turn leads to calcium oxalate stones.

XGP is a rare chronic inflammation of the kidney and constitutes less than $1 \%$ of chronic pyelonephritis. It is characterized by destruction of renal parenchyma and its replacement with granulomas, abscesses and collection of lipid laden macrophages (xanthoma cells) [1-3]. Females are more affected than males with a ratio of $1: 4$, and with a mean age varing from 45 to 55 years $[3,4]$. Though the exact mechanism of XGP is not clear, a number of predisposing factors have been implicated. The two most common predisposing factors are obstruction and infection of the genitor-urinary system. Calculi frequently stag horn type may be seen from $47 \%$ to $100 \%$ of cases. It is also more commonly seen in renal transplant recipients and diabetics [4,5]. In our patient, the combination of primary HPT and Crohn's disease leading to kidney stone formation and obstruction, in addition to her gender and age, are the most likely predisposing factors. XGP is commonly associated with Escherichia coli and Proteus infection; however bacterial outgrowth from urine culture is not necessary for diagnosis, as in our patient $[2,4]$.

The disease process affects the whole of the kidney in $85 \%$ (diffuse form). Focal forms are rare (15\%). The lesion is generally unilateral and can affect either kidney with equal frequency. Bilateral lesions are rare and are associated with poor outcome [2,3]. In the present case, a diffuse and unilateral form of XGP is observed. Symptoms are frequently nonspecific and include flank pain, fever, weight loss, anorexia and malaise. Uncommon

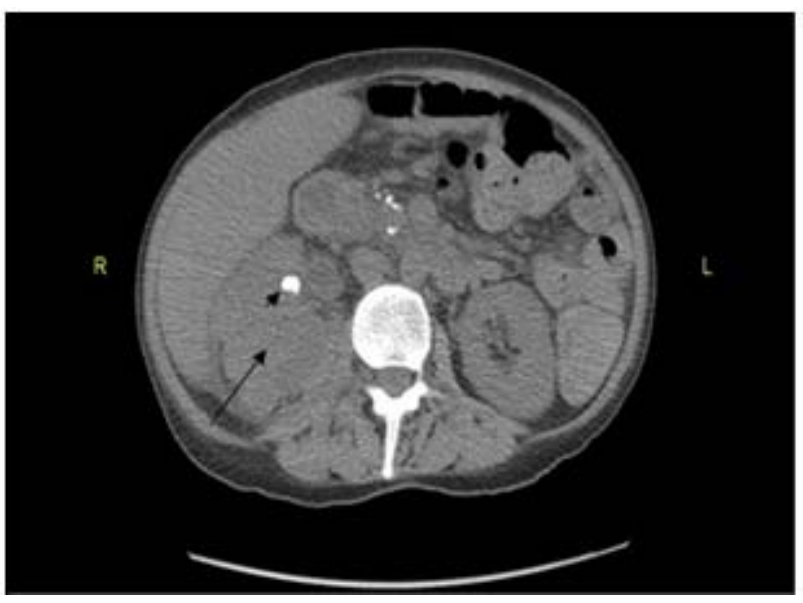

Figure 1. Non-contrast computed tomography of the abdomen and pelvis showing solid appearing soft tissue mass at the periphery of the mid and lower pole of the right kidney extending into the peri-nephric space (arrow) and renal stone (arrow head). 

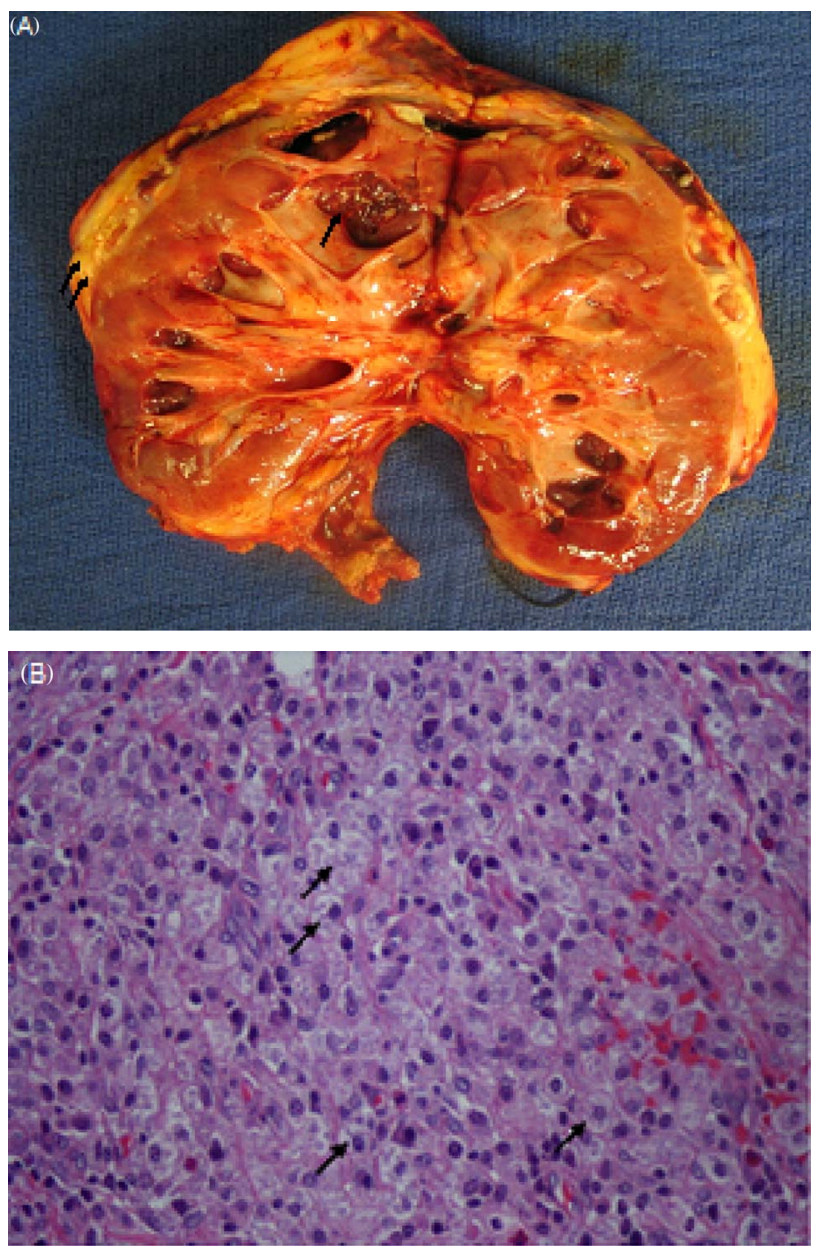

Figure 2. (A) Gross kidney specimen: Fat necrosis and scattered light yellow colored areas (double arrow) with diffuse yellow-red hemorrhagic tissue in the calyces (arrow). (B) Hematoxylin and eosin stain, original magnification $\times 200$, of renal biopsy showing lipid laden macrophage (xanthoma cells) (arrows) and inflammatory cells.

manifestation such as nephro-cutaneous fistula has also been described [6]. Physical exam may reveal palpable and tender flank mass. Clinical findings are easily confused with those of renal tumor in terms of its radiographic appearance and its ability to involve adjacent structures or organs [2,3]. The definitive diagnosis of this entity is achieved only by histopathology examination which shows the presence of lipid laden macrophage (xanthoma cells) [3].

Treatment of XGP consists of nephrectomy after the initial courses of antimicrobial therapy especially in the diffuse form since it is associated with a complete destruction of the kidney [4]. Cases of focal XGP treated with antibiotics alone have also been described [7,8]. Our patient underwent right nephrectomy and was discharged in a stable condition after 6 weeks of hospital stay and her discharge serum creatinine was $2.1 \mathrm{mg} / \mathrm{dL}$ (186 $\mu \mathrm{mol} / \mathrm{L})$.

In conclusion, XGP associated with Crohn's disease and primary HPT leading to calcium oxalate stones highlights the importance of early diagnosis of primary HPT and management of kidney stones, thus preventing from potentially incurable renal complications.

\section{REFERENCES}

[1] M. Levy, R. Baumal and A. A. Eddy, "Xanthogranulomatous Pyelonephritis in Children. Etiology, Pathogenesis, Clinical and Radiologic Features, and Management,” Clinical Pediatrics, Vol. 33, No. 6, 1994, pp. 360-366. doi:10.1177/000992289403300609

[2] T. Yoshino and H. Moriyama, "Case of the Diffuse Form of Xanthogranulomatous Pyelonephritis,” Case Reports in Urology, Vol. 2013, 2013, Article ID: 936035. doi:10.1155/2013/936035

[3] S. Goyal, M. Gupta and R. Goyal, "Xanthogranulomatous Pyelonephritis: A Rare Entity,” North American Journal of Medical Sciences, Vol. 3, No. 5, 2011, pp. 249-250. http://dx.doi.org/10.4297/najms.2011.3249

[4] L. Li and A. V. Parwani, "Xanthogranulomatous Pyelonephritis," Archives of Pathology \& Laboratory Medicine, Vol. 135, No. 5, 2011, pp. 671-674.

[5] H. M. Scarpero and J. B. Copley, "Xanthogranulomatous Pyelonephritis in a Renal Recipient,” American Journal of Kidney Diseases, Vol. 30, No. 6, 1997, pp. 846-848. http://dx.doi.org/10.1016/S0272-6386(97)90092-5

[6] G. Lee and J. H. Hong, "Xanthogranulomatous Pyelonephritis with Nephrocutaneous Fistula Due to Providencia rettgeri Infection," Journal of Medical Microbiology, Vol. 60, No. 7, 2011, pp. 1050-1052. doi:10.1099/jmm.0.028977-0

[7] C. I. Ho, Y. K. Wen and M. L. Chen, "Xanthogranulomatous Pyelonephritis Successfully Treated with Antibiotics Only," Journal of the Chinese Medical Association, Vol. 71, No. 12, 2008, pp. 643-645. doi:10.1016/S1726-4901(09)70008-5

[8] P. S. Brown Jr., M. Dodson, et al., "Xanthogranulomatous Pyelonephritis: Report of Nonsurgical Management of a Case and Review of the Literature," Clinical Infectious Diseases, Vol. 22, No. 2, 1996, pp. 308-314. doi:10.1093/clinids/22.2.308 